\title{
Enzyme-Free Glucose Sensor Based on Micro-nano Dualporous Gold-Modified Screen-Printed Carbon Electrode
}

\author{
Nguyen Xuan Viet ${ }^{1,2}$, Miyuki Chikae ${ }^{1}$, Yoshiaki Ukita ${ }^{1}$, and Yuzuru Takamura ${ }^{1}$ \\ ${ }^{1}$ School of Materials Science, Japan Advanced Institute of Science and Technology (JAIST), 1-1 \\ Asahidai, Nomi City, Ishikawa 923-1292, Japan. \\ ${ }^{2}$ Faculty of Chemistry, VNU University of Science, Vietnam National University, Hanoi, 19 Le Thanh \\ Tong, Hoan Kiem District, Ha Noi, Vietnam. \\ *E-mail: vietnx@vnu.edu.vn
}

doi: $10.20964 / 2018.09 .08$

Received: 18 December 2017 / Accepted: 28 June 2018 / Published: 5 August 2018

\begin{abstract}
In this work, an enzyme-free glucose sensor at neutral $\mathrm{pH}$ (7.4) has been developed based on a micronano dualporous (MNDP) gold-modified screen-printed carbon electrode (SPCE). The combination of MNDP gold and SPCE makes the device a compact, low-cost and reliable enzyme-free glucose sensor. MNDP gold was directly synthesized via an electrochemical deposition method on a carbon surface using a hydrogen bubble as a dynamic template. The obtained MNDP gold has a highly porous structure and is mechanically stable. The MNDP gold-modified SPCE was applied to glucose sensing. This enzyme-free sensor showed a wide linear range, with the logarithm of glucose concentration between 1.5 and $16 \mathrm{mM}$, a high sensitivity of $48.4 \mu \mathrm{A} \cdot \mathrm{mM}^{-1} \cdot \mathrm{cm}^{-2}$, and a limit of detection of $25 \mu \mathrm{M}$. It also exhibited exquisite selectivity with the common interference compounds in real samples. Moreover, this sensor successfully detects glucose levels in human blood serum with satisfactory results and functional recovery.
\end{abstract}

Keywords: Enzyme-Free, Glucose Sensor, Screen-Printed Carbon Electrode, Micro-Nano Dualporous Gold.

\section{$\underline{\text { FULL TEXT }}$}

(C) 2018 The Authors. Published by ESG (www.electrochemsci.org). This article is an open access article distributed under the terms and conditions of the Creative Commons Attribution license (http://creativecommons.org/licenses/by/4.0/). 